\title{
The effect of arabinoxylooligosaccharides on upper gastroduodenal motility and hunger ratings in humans
}

\author{
E.Scarpellini ${ }^{1}$ | E. Deloose ${ }^{1}$ (D) | R. Vos $^{1}$ | I. Francois ${ }^{2}$ | J.A. Delcour ${ }^{3}$ | \\ W. F. Broekaert ${ }^{3} \mid$ K. Verbeke $^{1}$ | J. Tack ${ }^{1}$ (D)
}

${ }^{1}$ Division of Gastroenterology, Department of Internal Medicine, TARGID, University Hospital Gasthuisberg, Leuven, Belgium

${ }^{2}$ Laboratory of Food Chemistry and Biochemistry \& Leuven Food Science and Nutrition Research Centre (LFoRCe), Catholic University of Leuven, Leuven, Belgium

${ }^{3}$ FUGEIA NV, Arenberg Science Park, Leuven, Belgium

Correspondence

J. Tack, Division of Gastroenterology, Department of Internal Medicine, University Hospital Gasthuisberg, Leuven, Belgium.

Email: jan.tack@med.kuleuven.be

Funding information

This study was supported by a Methusalem grant from the University of Leuven and by a restricted grant by Fugeia to Prof. J. Tack.

\begin{abstract}
Background and aims: Prebiotics such as Arabinoxylooligosaccharides (AXOS) are non-digestible, fermentable food ingredients stimulating growth/activity of colonic bacteria with enhanced carbohydrates fermentation (CF) in humans. The migrating motor complex (MMC) of the gastrointestinal tract has been recently identified as an important hunger signal, but no data are available yet on the role of acute CF on MMC activity and related hunger ratings. Thus, we aimed to study the effect of acute AXOS CF on MMC and hunger in humans.

Methods: A total of 13 healthy volunteers were randomized in a single-blind crossover placebo-controlled study where $9.4 \mathrm{~g}$ of AXOS or $10 \mathrm{~g}$ of maltodextrin and $1 \mathrm{~g}$ of unlabelled lactose ureide (LU) were given 12 hours prior to the study and, in the next morning, together with a pancake containing $500 \mathrm{mg}$ of ${ }^{13} \mathrm{C}-\mathrm{LU}$. In 10 hours after the meal, ${ }^{13} \mathrm{CO}_{2}$ and hydrogen excretion were determined every 15 minutes while hunger/appetite ratings every 2 minutes through a VAS questionnaire. Five hours after the meal, antroduodenal motility was measured using HRM.

Key Results: AXOS significantly increased CF (158 \pm 81 vs $840 \pm 464$ H2 ppm*minute, placebo vs AXOS, $P<.05)$ without affecting the orocecal transit time (OCTT). AXOS had no significant effect on the occurrence, origin, and duration of phase III and on the total number, origin, and duration of phases I and II. Hunger and appetite scores prior and after phase III were not affected by AXOS.
\end{abstract}

Conclusions: AXOS acutely increases colonic fermentation, but this neither affects OCTT, activity of the MMC, nor interdigestive hunger scores in man.

KEYWORDS

AXOS, high-resolution manometry, hunger

\section{1 | INTRODUCTION}

When energy supplies are low, hunger sensations will increase to stimulate eating behavior. During food intake, meal size will be controlled by the sensation of satiation. After meal intake, the balance between satiety and hunger sensation will determine the time interval to the next meal. ${ }^{1,2}$ During the fasting state, the upper gastroduodenal tract (GIT) initiates a particular contractility pattern known as the migrating motor complex (MMC). This complex can be divided into three phases of activity. Phase I is hallmarked by lack of contractile activity in both the stomach and small intestine. When contractions appear, phase II is starting and these contractions will increase in frequency until they will eventually form phase III. This last phase is the most characteristic phase of the MMC. It can start in the stomach, where these contractions have a frequency of 3 per minute, or in the small intestine, where the frequency is increased 
to 11 contractions per minute. ${ }^{3}$ Our group has recently shown that gastric phase III contractions can be a hunger signal in healthy volunteers, and this is altered in obesity and after bariatric surgery. ${ }^{4,5}$

However, the MMC is not the only determinant of hunger recurrence in the interdigestive state in humans. Gut microbiota is one of the emerging actors in the regulation of body metabolism and hunger ratings both in animal and human studies. ${ }^{6,7}$ In fact, recent animal and human studies support a role for intestinal microbiota in the regulation of gastroduodenal sensory-motor function. ${ }^{8}$ Moreover, diet-induced changes in body weight are accompanied by changes in microbial flora and "obese"/"lean" colonic microbial populations are associated with correspondent organisms' metabolic assets. ${ }^{9,10}$ Gastrointestinal microbiota can be modulated by antibiotics, prebiotics, and probiotics. Prebiotics are "non-digestible, fermentable food ingredients that can affect the host by selectively stimulating the growth/activity of beneficial bacteria in the colon and thereby improve host health." ${ }^{9}$ Prebiotics like inulin and fructooligosaccharides (FOS) are evaluated for their potential to lower appetite and induce early satiety. ${ }^{10}$ Interactions between prebiotics and the MMC have not been studied in depth.

Arabinoxylooligosaccharides (AXOS) are fragmentation products of arabinoxylans (AX), occurring in many cereal grains, consisting of a main chain of beta-1,4-linked D-xylopyranosyl units to which O-2 and/or O-3-L-arabinofuranosyl units are linked. ${ }^{11-15}$ AXOS are readily fermented by colonic bacteria with different beneficial metabolic effects. ${ }^{16,17}$ In chickens, a significant increase in cecal bifidobacteria has also been reported, and in rats, AXOS increased the fecal levels of short-chain fatty acids (SCFA). ${ }^{17}$ In humans, AXOS does not affect gastric-emptying or orocecal transit time (OCTT) but leads to a significant shift from urinary to fecal ${ }^{15} \mathrm{~N}$-excretion, suggesting a higher uptake or incorporation by bacteria due to the stimulation of colonic bacterial growth and/or metabolic activity modulation due to carbohydrate fermentation ${ }^{18,19}$ and an increase in fecal total SCFA concentrations. ${ }^{20}$

Only a few and inconsistent data are available on the effect of acute prebiotic administration on the regulation of hunger, appetite, and upper gastroduodenal motility in man. In fact, chronic administration of FOS can lower appetite through the production of SCFA which are potentially involved in the modulation of gastroduodenal sensorymotor function, and effects of AXOS on nutrient tolerance only have been studied by our group with no significant effects vs placebo. ${ }^{21-25}$ However, the effect of prebiotics on appetite upon acute administration has not been studied in detail. ${ }^{21-25}$

Thus, the aim of this study was to investigate the influence of acute AXOS administration on the activity of the MMC and hunger scores in man.

\section{2 | MATERIALS AND METHODS}

\section{1 | Subjects}

Studies were performed in 13 healthy volunteers (six men; mean age, $32.9 .8 \pm 7.8$ years; range, $18-42$ years) with a mean BMI of $21.6 \pm 1.6 \mathrm{~kg} / \mathrm{m}^{2}$. Exclusion criteria were gastrointestinal complaints,

\section{Key Points}

- Acute AXOS administration although followed by a significant colonic fermentation does not affect upper gastroduodenal motility and hunger feeling.

- We aimed to investigate whether the interplay between upper gastroduodenal motility and hunger was affected by acute colonic fermentation after AXOS administration.

- Thirteen healthy volunteers underwent two randomized single-blind antroduodenal high-resolution manometry studies with hunger VAS ratings determination after AXOS or maltodextrin (placebo), at least 1 week apart, with simultaneous orocecal transit time and colonic fermentation assessment by ${ }^{13} \mathrm{C}$-lactose ureide and $\mathrm{H}_{2}$ breath tests.

- Acute AXOS administration, although associated to a significant colonic fermentation, does not significantly affect orocecal transit time, upper gastroduodenal interdigestive motility, and hunger and appetite ratings in man.

intake of antibiotics, or medication influencing gut transit and/or microbiota during the previous 3 months, abdominal surgery, and pregnancy. During the study, subjects were allowed to eat their usual diets but were asked to have a regular eating pattern (three meals per day). The intake of food substances containing probiotics and/or prebiotics was forbidden, whereas the consumption of food containing natural small amounts of inulin and/or FOS such as chicory, artichoke, garlic, onions, green banana, leek, and soya beans was limited to once per week. At the time of inclusion, all subjects were informed about proand prebiotics and the food products containing pro- and/or prebiotics. They were asked to read food labels carefully to check whether pro- and/or prebiotics had been added.

The study protocol was approved by the Ethics Committee of the University Hospital UZ Leuven (Belgium) and written informed consent was obtained from each subject prior to inclusion in the study.

\section{2 | Study design}

Volunteers were treated with AXOS or placebo in a single-blind, randomized, crossover fashion. During the $24 \mathrm{~h}$ treatment periods, either $2 \times 10 \mathrm{~g}$ maltodextrin (placebo) or $2 \times 9.4 \mathrm{~g}$ AXOS was administered orally, with a washout period of at least 1 week between the two 24-hour treatment periods. Intake of maltodextrin or AXOS during the 24-hour treatment period was scheduled during the evening of day 0 and the morning of day 1 (Figure 1). The measurement of antroduodenal motility started 5 hours after the ingestion of carbohydrates to assure that the measurement occurred during colonic fermentation. To confirm that experiments were performed during the fermentation phase, OCTT, and colonic fermentation after AXOS or placebo were monitored during 10 hours using a ${ }^{13} \mathrm{C}$-lactose ureide breath test and hydrogen breath test ${ }^{18}$ starting from the morning of day 1 (Figure 1 ). 


\section{Day $0 \quad$ Day 1}

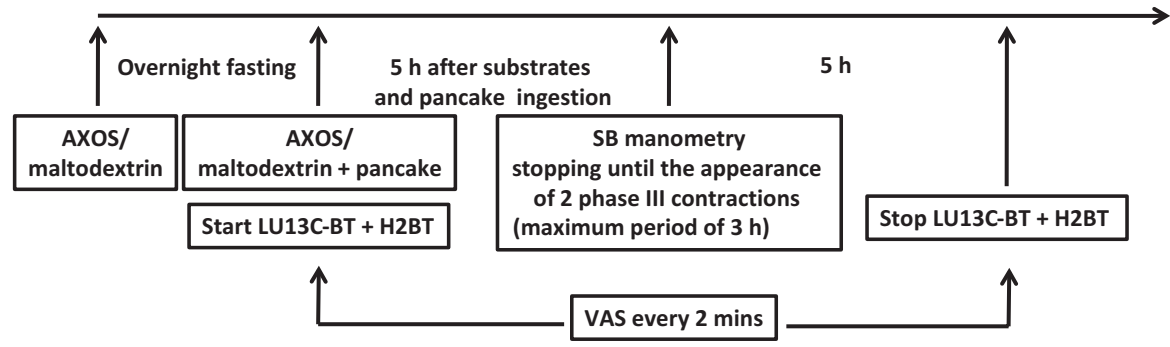

FIGURE 1 Study design. Volunteers were treated with AXOS or placebo in a single-blind, randomized, crossover fashion, taking the carbohydrates on the evening of day 0 and the morning of day 1 . The collection of ${ }^{13} \mathrm{C}$-lactose ureide and hydrogen breath samples started $30 \mathrm{~min}$ prior to the ${ }^{13} \mathrm{C}$-lactose ureide labelled meal $(244 \mathrm{kcal})$, and samples were taken every 15 minutes for 10 hours. Antroduodenal manometry was planned 5 hours after the meal and continued until the passage of two phase III contractions. At 2-minute intervals, volunteers indicated scores for hunger and appetite on a visual analog scale (VAS) of $10 \mathrm{~cm}$ with endpoints

During manometry, the subjects were positioned in a comfortable sitting position with the knees bent $\left(80^{\circ}\right)$ and the trunk upright in a specifically designed bed. Gastroduodenal motility was recorded during the fasting state until the appearance of two phase III contractions of the MMC or for a maximum period of 3 hours. At 2-minute intervals, volunteers indicated scores for hunger and appetite on a visual analog scale (VAS) with endpoints 5 hours before and after antroduodenal manometry.

\section{3 | Substrates}

The AXOS preparation used in the present study was wheat bran extract (Brana Vita ${ }^{\circledR} 200$ ) and was produced from wheat bran by Fugeia NV (Leuven, Belgium), using a procedure based on that described previously. ${ }^{18}$ The AXOS preparation had an AXOS content of $75 \%$, an average degree of polymerization of 5 , and an average degree of arabinose substitution of 0.22 .

During the 24-hour treatment period, subjects were treated with $2 \times 12.5 \mathrm{~g}$ of the crude AXOS preparation, corresponding to $2 \times 9.4 \mathrm{~g}$ of pure AXOS, taking into account the AXOS content in the preparation (75\%). Maltodextrin (Maldex 150; Syral Belgium, Aalst, Belgium) was used as placebo and was administered at $2 \times 10 \mathrm{~g}$ doses. Both substrates were dissolved in warm water $(330 \mathrm{ml}$ for $9.4 \mathrm{~g}$ AXOS or $330 \mathrm{ml}$ for $10 \mathrm{~g}$ maltodextrin) before intake.

\section{$2.4 \quad \mathrm{H}_{2}$ and ${ }^{13} \mathrm{C}$-Lactose ureide (LU) breath tests}

The evening of day $0,1 \mathrm{~g}$ unlabeled lactose ureide (LU) was administered in a glass of $15 \mathrm{ml}$ of water to induce the proper enzyme activity in the colonic bacteria. After an overnight fast, the volunteers came to the endoscopy department at $7.30 \mathrm{Am}$. Two breath samples were taken 30 minutes before the ingestion of the test meal in order to determine the basal values of ${ }^{13} \mathrm{CO}_{2}$ and hydrogen. After the consumption of the test meal (pancake consisting of $8.4 \mathrm{~g}$ protein, $11.2 \mathrm{~g}$ fat, and $26.7 \mathrm{~g}$ carbohydrate (244 kcal), containing $500 \mathrm{mg}$ lactose- $\left[{ }^{13} \mathrm{C}\right]-$ ureide $\left({ }^{13} \mathrm{C}\right.$-LU) $)$, breath samples were taken in duplicate at 15 -minute intervals for 10 hours to measure ${ }^{13} \mathrm{CO}_{2}$ excretion (as measure of OCTT) and hydrogen excretion (as indication of carbohydrates bacterial fermentation in the colon). All samples were collected in exetainers (Europa Scientific, Crewe, UK). ${ }^{18}$

\section{5 | Antroduodenal manometry}

Recording of antroduodenal intraluminal pressures was performed using a high-resolution solid-state manometry catheter (36 channels, $1 \mathrm{~cm}$ spaced, Manoscan 360; Sierra Scientific Instruments, Los Angeles, CA, USA; Manoview analysis software v2.0.1). The catheter was introduced through the nose and advanced through the pylorus under fluoroscopic guidance. The position of the catheter was fine tuned during pressure measurements to insure simultaneous visualization of the lower esophageal sphincter and pressures in the fundus, antrum, and proximal part of the duodenum. Once the catheter was in place, it was fixed to the subject's nose with tape. Measurements began after a 30-minute recovery period. During the live measurement, phases of the $\mathrm{MMC}$ were recognized using predefined definitions. ${ }^{4}$

\section{6 | Data analysis}

\subsection{1 $\mid \mathrm{H}_{2}$ and ${ }^{13} \mathrm{C}$-LU breath tests}

The isotopic enrichment of $\mathrm{CO}_{2}$ in breath samples was analyzed using isotope ratio mass spectrometry (ABCA, Europa Scientific, Crewe, UK). OCTT was calculated by determining the time between the intake of ${ }^{13} \mathrm{C}$-LU and the detection of a significant increase (> 2.5 standard deviation above mean) of ${ }^{13} \mathrm{CO}_{2}$ above baseline in the breath samples. Hydrogen excretion was measured with a hydrogen monitor (part per million, ppm) (M.E.C., Brussels, Belgium) and cumulative hydrogen excretion was calculated over a 10 -hour period AUC. ${ }^{18}$

\section{7 | Antroduodenal manometry}

An interpolated thermal compensation was done on the manometry recording to correct thermal drift during the measurement. Through visual analysis, the most antral recording site was identified as the channel displaying up to three contractions per minute and those in the duodenum as the most proximal channel displaying up to 12 
contractions per minute. The different phases of the MMC were identified according to previously described criteria. ${ }^{3,4}$

\subsubsection{Hunger and appetite scores}

The area under the curve (AUC) of hunger and appetite scores were determined for each participant 60 minutes before and 30 minutes after the occurrence of a phase III contraction of either origin. These times were chosen to include most of the phase II preceding and the phase I following phase III.

\section{8 | Statistical analysis}

The study was powered to detect $30 \%$ differences between AXOS and placebo treatment in relevant manometric and hunger rating parameters. ${ }^{4,5,18,19}$ All data are presented as mean \pm standard error of the mean (SEM). Paired student's $t$ tests were used to compare mean values between both treatments for OCTT and colonic fermentation. Duration of the different phases of the MMC and origin of phase III after AXOS or placebo administration were compared using paired $t$ test, Chi-square, and Fisher's exact test, respectively. AUC of hunger was compared between the two treatments both before and after phase III using paired $t$ tests. Differences were considered to be significant at the $5 \%$ level.

\section{3 | RESULTS}

All subjects completed both arms of the study. Of 13 subjects, 8 reported mild bloating during the AXOS experiments session only.

\section{$3.1 \mid \mathrm{H}_{2}$ and ${ }^{13} \mathrm{C}$-LU breath tests}

AXOS administration did not significantly affect the OCTT (351.3 \pm 55 vs $351.5 \pm 96$ minutes, placebo vs $A X O S, P=N S)$ but significantly increased carbohydrate colonic fermentation (158 \pm 81 vs $840 \pm 464$ $\mathrm{H} 2 \mathrm{ppm}^{*}$ minute, placebo vs AXOS, $\mathrm{P}<$.05) (Figure 2).

\section{2 | Antroduodenal manometry}

Total manometry recording times were $237 \pm 50$ and $245 \pm 40$ minutes for placebo and AXOS, respectively $(P=N S)$. A total of 24 and 30 phase III contractions were registered during placebo and AXOS treatment, respectively. An average number of $1.77 \pm 0.34$ and $1.92 \pm 0.26$ phases III (F3) were registered in the placebo and AXOS arms, respectively ( $t$ test, placebo vs AXOS, $P=N S$ ). The average number of F3s with gastric (G) origin was not significantly affected by AXOS (0.46 \pm 0.18 vs $0.62 \pm 0.18$, $t$ test, placebo vs AXOS, $P=N S$ ) nor were those of small bowel $(S B)$ origin $(1.38 \pm 0.31$ vs $1.69 \pm 0.17, t$ test, placebo vs AXOS, $P=N S)$.

AXOS did not significantly alter the duration of gastric phase III contractions ( $1.6 \pm 0.3$ vs $2 \pm 0.2$ minutes, placebo vs AXOS, NS) but tended to increase the duration of phase III contractions starting in the duodenum ( $6.2 \pm 4$ vs $8.3 \pm 5$ minutes, placebo vs AXOS, $P=.07$ ) (Table 1) although this tendency was lost after correction for multiple testing.

AXOS did not change durations of phase I (F1) and phase II (F2) ( $23 \pm 15$ vs $31 \pm 22$ and $206 \pm 82$ vs $204 \pm 90$ minutes for F1 and F2, respectively, $t$ test, placebo vs AXOS, both $P=$ NS) (Table 1 ).

\section{3 | Hunger scores}

The hunger and appetite scores, expressed as AUC, 60 minutes before F3 occurrence were not significantly affected by AXOS, compared to placebo $(91 \pm 18.6$ vs $69 \pm 17.5$ and $108.6 \pm 16.2$ vs $80.6 \pm 16.6 \mathrm{~cm}^{*}$ minute for hunger and appetite AUC, respectively, $t$ test, both $P=.06$ ). The same result was observed after occurrence of the F3 ( $t$ test, both $P=N S$ ) (Figure 3 ).

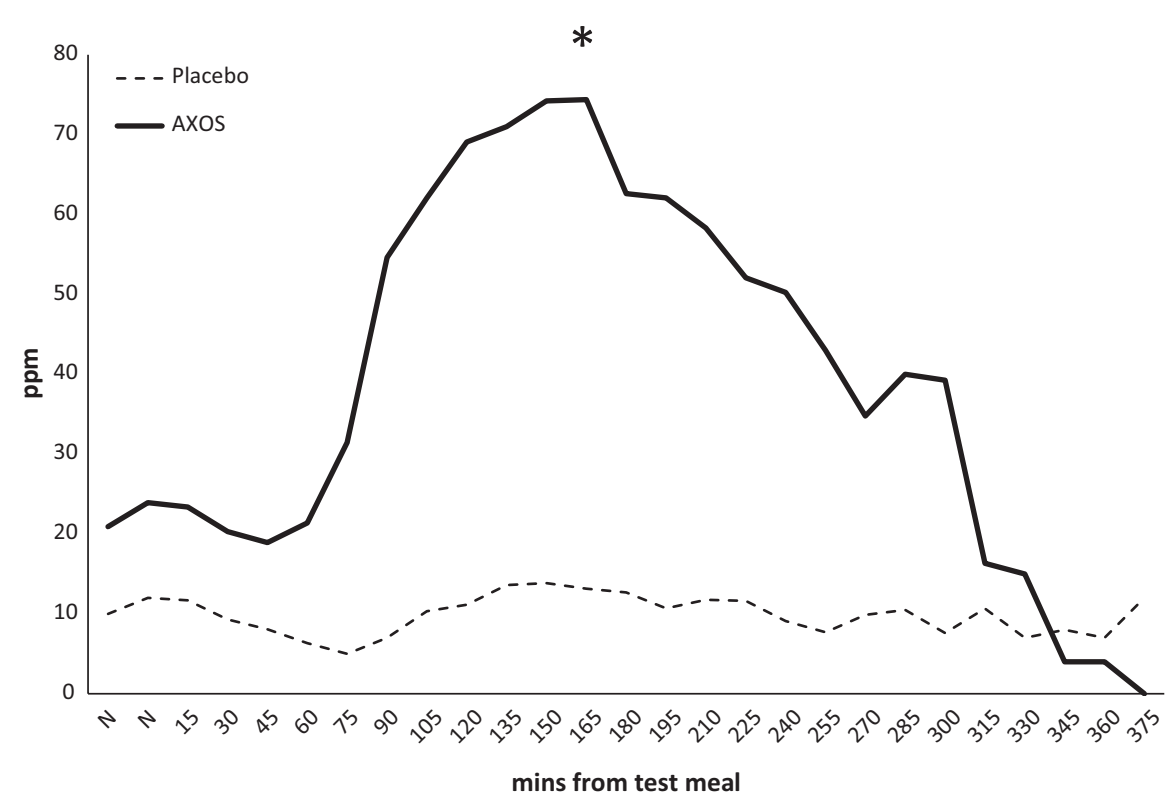

FIGURE 2 Colonic fermentation (CF) assessed by hydrogen breath test: AXOS significantly increased carbohydrate colonic fermentation vs placebo $\left({ }^{*}<.05\right) ; \mathrm{N}$ are the two baseline hydrogen breath samples before test meal ingestion 
TABLE 1 Duration of the phases of the migrating motor complex

\begin{tabular}{lccc} 
MMC phase & Placebo & AXOS & P value \\
\hline Gastric phase III & $1.6 \pm 0.3$ & $2.0 \pm 0.2 \mathrm{~min}$ & NS \\
\hline Duodenal phase III & $6.2 \pm 4$ & $8.3 \pm 5^{\mathrm{a}} \mathrm{min}$ & .07 \\
\hline Phase I & $23 \pm 15$ & $31 \pm 22 \mathrm{~min}$ & NS \\
Phase II & $206 \pm 82$ & $204 \pm 90 \mathrm{~min}$ & NS \\
\hline
\end{tabular}

${ }^{a} t$ test, $P=.07$, however, the difference, already not statistically significant, was lost (NS) after correction for multiple testing.

\section{4 | DISCUSSION}

The aim of the current study was to investigate the effect of shortterm changes in carbohydrate colonic fermentation after acute AXOS administration on upper gastroduodenal motility and hunger ratings in healthy volunteers. We observed that acute AXOS colonic fermentation does not significantly affect the upper gastrointestinal tract interdigestive motility and does not significantly alter hunger ratings in man.

These findings are in line with the results of previous studies where different AXOS concentrations did not alter gastric-emptying time (not measured in the present study) and OCTT, while there was significantly enhanced CF compared to control (maltodextrin). ${ }^{18}$ In fact, in the present study, we confirmed that the OCTT, evaluated with the validated LU-breath test, was not significantly affected by AXOS.

As cited in the introduction, in the literature only a few studies evaluated the effect of acute prebiotic fermentation on upper gastroduodenal motility in man. Most studies were performed in pediatric subjects and have shown contradictory results on relief of childhood constipation. ${ }^{23}$ However, these studies never directly measured the upper interdigestive motility but used transit measurements such as gastric-emptying time and OCTT. Moreover, these studies use a variety of prebiotic preparations, different from $A X O S$, although several of them belong to the FOS-derived group. In the present study, we observed that acute AXOS administration does not alter phase III contractions compared to placebo treatment. This finding is perhaps in line with literature and is not in favor of acute prebiotic fermentation effect on upper gastroduodenal motility.

In the present study, acute AXOS colonic fermentation did not significantly lower hunger ratings in man. While several studies showed a hunger lowering effect of long-term administration of prebiotics in healthy volunteers, ${ }^{24}$ only few studies have investigated the acute effects of prebiotics on hunger and appetite ratings. Peters et al. provided healthy volunteers with a bar containing $8 \mathrm{~g}$ oligofructose or nonoligofructose to be eaten at breakfast and lunch on day 1 and breakfast only on day 2. No significant effects of treatment were found on satiety ratings or ad libitum energy intake postprandially, a test setup which is comparable with the nutrient tolerance test we used in a previous study from our group. ${ }^{24-26}$ Conversely, Archer and colleagues reported a 24-hour energy intake significantly lowered by $24 \mathrm{~g}$ inulin supplementation in healthy volunteers. In this study, satiety ratings were not significantly altered, but the control and inulin-containing meals were not matched for energy intake. ${ }^{27}$ Another study using inulin showed similar findings: yoghurt containing $6 \mathrm{~g}$ inulin-type fructans significantly
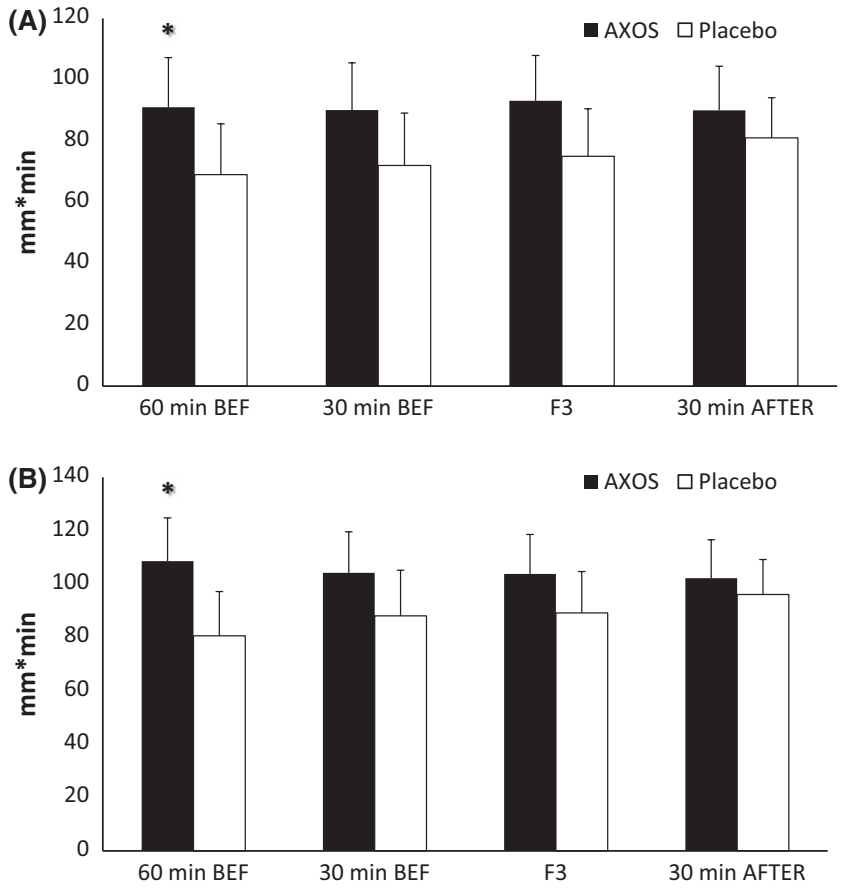

FIGURE 3 Hunger ratings in the fasting state: (A) The hunger and (B) appetite scores 60 minutes before F3s occurrence tended to be higher after AXOS than placebo $\left({ }^{*} P=.06\right)$; this tendency was lost 30 minutes before, at the moment of F3 occurrence, and 30 minutes after F3 occurrence $(P=N S)$

decreased hunger in a controlled setting in healthy volunteers. ${ }^{28}$ However, the overall energy intake (preload and ad libitum intake) was higher than in the control condition. Finally, Darzi et al. carried out an acute three-way crossover study to investigate the effects on appetite of inulin (22.4 g) vs L-rhamnose (25.5 g) as a component of breakfast and lunch compared to control non-digestible carbohydrates, following a 6-day run-in period. ${ }^{29} \mathrm{~L}$-rhamnose was selected because it favors production of propionate, which has been implicated in appetite suppression by acting on the SCFA receptor FFA3 to promote leptin expression and production of peptide $Y Y$ (PYY). ${ }^{10,30}$ However, the treatments had no influence on appetite, and there were no significant differences between treatments for ad libitum energy intake, intake during the 24-hour period following the breakfast preload, nor on the mean daily intake during the run-in period. ${ }^{21}$ Finally, all these studies used satiety ratings measurement that is different from the present study where we aimed to measure hunger and appetite ratings with a VAS scale at short intervals and calculated the AUC as done in our previous studies. ${ }^{4,5}$

Indeed, results from the present study do not show a potential role for acute prebiotic fermentation on both hunger and appetite in humans.

A limitation of the present study is the lack of measurements of gastrointestinal hormone plasma levels known to influence hunger ratings such as glucagon-like peptide-1 (GLP-1), PYY, motilin, ghrelin, and somatostatin. As previously discussed, it is conceivable that their release can be modulated by an increased SCFA concentration arising from prebiotic fermentation. ${ }^{21,31,32}$ On the other hand, it seems less likely that acute AXOS administration, without any run-in period, 
could affect their secretion, as has been demonstrated by several longterm prebiotics administration vs acute studies. ${ }^{21-29}$

Although there is a lack of effect of acute AXOS administration on both interdigestive motility and hunger ratings in the present study, this does not exclude significant effects with higher doses or during longer term administration. The latter is a very interesting future direction. In fact, it is conceivable that both long-term increased colonic fermentation and gut microflora changes could affect OCTT, hunger and appetite ratings in humans.

Indeed, prebiotics are well known to be able to modulate gut microbiota and hunger ratings in animal and human studies after chronic administration. ${ }^{21-29}$ Inulin supplementation of male mice fed on a highfat diet led to a significant reduction in weight gain, body fat deposition vs the control group on high-fat diet only. Interestingly, there was a significant increase in both bifidobacteria and lactobacillus and increased SCFA production. ${ }^{33}$ These findings could be relevant for hunger and appetite modulation in humans.

Interestingly, through its prebiotic effect, chronic AXOS administration can modulate gut microbiota leading to translocation of Akkermansia muciniphila from the cecum to colon and feces in an experimental mouse model. ${ }^{34}$ Akkermansia muciniphila is the main microorganism with ability to live on and break down mucus within the lower gastrointestinal tract. In addition, there is an inverse correlation between gut Akkermansia muciniphila concentration and the onset of obesity. ${ }^{34}$ Thus, we can hypothesize that long-term AXOS administration could also affect hunger and appetite ratings in man. Indeed, this part of the future research agenda needs a careful systematic organization because the effects of fibers, probiotics, and gut microbiota modulation on hunger and appetite can be broad and heterogeneous.

The current study was limited to daytime measurement, as if focused on hunger and appetite. It would be interesting to study the potential effect of AXOS on nocturnal interdigestive motility too, as it is well known that diurnal and nocturnal interdigestive MMC have different patterns; nocturnal phases III are more frequent, last longer, with a lower amplitude than the diurnal phases. ${ }^{35}$ On the other hand, hunger is only relevant during awake time. A detailed study of nocturnal interdigestive motility would need a different study design, with prolonged and perhaps ambulatory small bowel manometry.

To conclude, this study showed that acute AXOS administration and its subsequent carbohydrate fermentation do not affect upper interdigestive gastroduodenal motility and hunger ratings in man. These results await confirmation in further studies of the effect of long-term and higher dose administration of AXOS on gastroduodenal motility and hunger ratings in humans.

\section{DISCLOSURES}

No competing interests for any of the authors.

\section{AUTHOR CONTRIBUTIONS}

Emidio Scarpellini and Jan Tack designed the study; Emidio Scarpellini conducted the experiments; Emidio Scarpellini, Jan Tack, Eveline
Deloose, and Rita Vos analyzed the data; Emidio Scarpellini, Kristin Verbeke, and Jan Tack wrote the manuscript; Kristin Verbeke, Isabelle Francois, Jan Delcour, Willem Broekaert, and Jan Tack revised the manuscript.

\section{ORCID}

E. Deloose iD http://orcid.org/0000-0001-8694-7745

J. Tack (iD http://orcid.org/0000-0002-3206-6704

\section{REFERENCES}

1. Camilleri M, Grudell AB. Appetite and obesity: a gastroenterologist's perspective. Neurogastroenterol Motil. 2007;19:33-41.

2. Janssen P, Vanden Berghe P, Verschueren S, Lehmann A, Depoortere I, Tack J. Review article: the role of gastric motility in the control of food intake. Aliment Pharmacol Ther. 2011;33:880-894.

3. Deloose E, Janssen P, Depoortere I, Tack J. The migrating motor complex: control mechanisms and its role in health and disease. Nat Rev Gatroenterol Hepatol. 2012;9:271-285.

4. Tack J, Deloose E, Ang D, et al. Motilin-induced gastric contractions signal hunger in man. Gut. 2014;65:214-224.

5. Deloose E, Janssen P, Lannoo M, van der Schueren B, Depoortere I, Tack J. Higher plasma motilin levels in obese patients decrease after Roux-en-Y gastric bypass surgery and regulate hunger. Gut. 2016;65:1110-1118.

6. Turnbaugh PJ, Ley RE, Mahowald MA, Magrini V, Mardis ER, Gordon JI. An obesity-associated gut microbiome with increased capacity for energy harvest. Nature. 2006;444:1027-1031.

7. De Wouw M, Schellekens H, Dinan TG, Cryan JF. Microbiota-GutBrain Axis: modulator of Host Metabolism and Appetite. J Nutr. 2017;147:727-745.

8. Ley RE, Turnbaugh PJ, Klein S, Gordon Jl. Microbial ecology: human gut microbes associated with obesity. Nature. 2006;444:1022-1023.

9. Ritchie ML, Romanuk TN. A meta-analysis of probiotic efficacy for gastroduodenal diseases. PLoS ONE. 2012;7:e34938. Epub 2012 Apr 18.

10. Roberfroid M, Gibson GR, Hoyles L, et al. Prebiotic effects: metabolic and health benefits. Br J Nutr. 2010;104:S1-S63.

11. Terpend K, Possemiers S, Daguet D, Marzorati M. Arabinogalactan and fructo-oligosaccharides have a different fermentation profile in the simulator of the human intestinal microbial ecosystem (SHIME ${ }^{\circledR}$ ). Environ Microbiol Rep. 2013;5:595-603.

12. Courtin CM, Delcour JA. Arabinoxylans and endoxylanases in wheat flour bread-making. J Cereal Sci. 2002;35:225-243.

13. Holloway WD, Tasmanjones C, Bell E. Hemicellulose component of dietary fiber. Am J Clin Nutr. 1980;33:260-263.

14. Lu ZX, Walker KZ, Muir JG, O'Dea K. Arabinoxylan fiber improves metabolic control in people with Type II diabetes. Eur J Clin Nutr. 2004;58:621-628.

15. Yamada $\mathrm{H}$, Itoh $\mathrm{K}$, Morishita $\mathrm{Y}$, Taniguchi $\mathrm{H}$. Structure and properties of oligosaccharides from wheat bran. Cereal Foods World. 1993;38:490-492.

16. Grootaert C, Delcour JA, Courtin CM, Broekaert WF, Verstraete W, van de Wiele T. Microbial metabolism and prebiotic potency of arabinoxylan oligosaccharides in the human intestine. Trends Food Sci Tech. 2007;18:64-71.

17. Broekaert WF, Courtin CM, Verbeke K, van de Wiele T, Verstaete W, Delcour JA. Prebiotic and other health-related effects of cerealderived arabinoxylans, arabinoxylan-oligosaccharides, and xylooligosaccharides. Crit Rev Food Sci Nutr. 2011;51:178-194.

18. Cloetens L, de Preter V, Swennen K, et al. Dose-response effect of arabinoxylooligosaccharides on gastroduodenal motility and on 
colonic bacterial metabolism in healthy volunteers. J Am Coll Nutr. 2008;27:512-518.

19. François IEJA, Lescroart O, Veraverbeke WS, et al. Effects of a Wheat Bran Extract containing arabinoxylan oligosaccharides on gastroduodenal health parameters in healthy adult human volunteers: a doubleblind, randomized, placebo-controlled, crossover trial. $\mathrm{Br} J$ Nutr. 2012;108:2229-2242.

20. Swennen K, Courtin CM, Lindemans GCJE, Delcour JA. Large scale production and characterization of wheat bran arabinoxylooligosaccharides. J Sci Food Agric. 2006;86:1722-1731.

21. Darzi J, Frost GS, Robertson M. Conference on 'Nutrition and health: cell to community' Postgraduate Symposium Do SCFA have a role in appetite regulation? Proceedings of the Nutrition Society. 2011;70:119-128.

22. Finney M, Smullen J, Foster HA, Brokx S, Storey DM. Effects of low doses of lactitol on faecal micro flora, $\mathrm{pH}$, short chain fatty acids and gastroduodenal symptomatology. Eur J Nutr. 2007;46:307-314.

23. Indrio F, Riezzo G, Raimondi F, Bisceglia M, Cavallo L, Francavilla R. Effects of probiotic and prebiotic on gastroduodenal motility in newborns. J of Physiol Pharmacol. 2009;60:27-31.

24. Cani PD, Lecourt E, Dewulf EM, et al. Gut microbiota fermentation of prebiotics increases satietogenic and incretin gut peptide production with consequences for appetite sensation and glucose response after a meal. Am J Clin Nutr. 2009;90:1236-1243.

25. Scarpellini E, Deloose E, Vos R, et al. The effect of arabinoxylooligosaccharides on gastric sensory-motor function and nutrient tolerance in man. Neurogastroenterol Motil. 2016;28:1194-1203.

26. Peters HP, Boers HM, Haddeman E, Melnikov SM, Qvyjt F. No effect of added beta-glucan or of fructooligosaccharide on appetite or energy intake. Am J Clin Nutr. 2009;89:58-63.

27. Archer BJ, Johnson SK, Devereux HM, Baxter AL. Effect of fat replacement by inulin or lupin-kernel fibre on sausage patty acceptability, post-meal perceptions of satiety and food intake in men. Br J Nutr. 2004;91:591-599.

28. Perrigue MM, Monsivais $P$, Drewnowski A. Added soluble fiber enhances the satiating power of low-energy-density liquid yogurts. J Am Diet Assoc. 2009;109:1862-1868.
29. Vogt JA, Pencharz PB, Wolever MS. L-Rhamose increases serum propionate in humans. Am J Clin Nutr. 2004;80:89-94.

30. Xiong Y, Miyamoto N, Shibata K, et al. Short-chain fatty acids stimulate leptin production in adipocytes through the $\mathrm{G}$ protein-coupled receptor GPR41. Proc Natl Acad Sci USA. 2004;101:1045-1050.

31. Cherbut $C$. Motor effects of short-chain fatty acids and lactate in the gastroduodenal tract. Proceedings of the Nutrition Society. 2003;62:95-99.

32. Anastasovska J, Arora T, Sanchez Canon GJ, et al. Fermentable carbohydrate alters hypothalamic neuronal activity and protects against the obesogenic environment. Obesity (Silver Spring). 2012;20:1016-1023.

33. Van den Abbeele P, Gérard P, Rabot $S$, et al. Arabinoxylans and inulin differentially modulate the mucosal and luminal gut microbiota and mucin-degradation in humanized rats. Environ Microbiol. 2011;13:2667-2680.

34. Schneeberger M, Everard A, Gómez-Valadés AG, et al. Akkermansia muciniphila inversely correlates with the onset of inflammation, altered adipose tissue metabolism and metabolic disorders during obesity in mice. Sci Rep. 2015;5:16643.

35. Bouin M, Sassi A, Savoye G, Denis P, Ducrotté P. Effects of enteral feeding on antroduodenal motility in healthy volunteers with 2 different fiber-supplemented diets: a 24-hour manometric study. JPEN J Parenter Enteral Nutr. 2004;28:169-175.

How to cite this article: Scarpellini E, Deloose E, Vos R, et al.

The effect of arabinoxylooligosaccharides on upper gastroduodenal motility and hunger ratings in humans. Neurogastroenterol Motil. 2018;30:e13306.

https://doi.org/10.1111/nmo.13306 